\title{
ANÁLISE DO RENDIMENTO DOS ALUNOS COM O USO DO MOODLE COMO FERRAMENTA DE APOIO NA DISCIPLINA PRESENCIAL MÚSICA BRASILEIRA
}

\author{
Analysis students performances using Moodle as supporting \\ tool in the Brasilian music course
}

\author{
Análisis del rendimiento de los alumnos com el uso del Moodle \\ como herramienta de apoyo en la assignatura música Brasileña
}

\section{Rivaldo José de Souza Silva ${ }^{1}$}

\section{RESUMO}

O presente artigo tem como objetivo apresentar os resultados sobre a utilização do AVA Moodle - UFAL como ferramenta de apoio às aulas presenciais na disciplina Música Brasileira ministrada no Curso de Música da Universidade Federal de Alagoas - UFAL. Na Introdução, há uma fundamentação sobre o uso das TIC para a renovação pedagógica. Os autores citados criticam o ensino tradicional centrado no professor e defendem a junção entre educação presencial e a distância, numa combinação de recursos. A pesquisa vem discutir a seguinte pergunta: de que maneira o uso do Moodle e os recursos das TIC se traduzem em resultado expressivo na disciplina presencial Música Brasileira? Na seção Materiais e Métodos, foram utilizadas aulas no AVA Moodle - UFAL com apostilas para leitura, questionários (dos tipos ensaio, múltipla escolha, respostas embutidas, verdadeiro ou falso), fórum, vídeos-documentários, podcasts, wikis, um grupo para a turma no WhatsApp, e um questionário semiestruturado de pesquisa para os alunos. Na seção Resultados e Discussões, são disponibilizadas e analisadas as respostas dos alunos ao questionário de pesquisa, e a participação nas aulas propostas no AVA Moodle - UFAL no primeiro e segundo bimestres em forma de gráficos e porcentagem em comparação com os resultados obtidos em pesquisas de autores e autoras que utilizaram o Moodle como ferramenta de apoio em disciplinas presenciais. Nas Considerações Finais, concluímos que o uso do AVA Moodle - UFAL transformou-se num lugar de encontro e discussão dos alunos e do professor, principalmente no segundo bimestre quando foram ampliados os recursos virtuais utilizados. Dessa forma, o Moodle mostrouse uma ferramenta poderosa para o ensino, aprendizagem e interação.

\footnotetext{
${ }^{1}$ Universidade Federal de Alagoas - Maceió, Alagoas - E-mail: duduisouza@ hotmail.com - ORCID: http://orcid.org/0000-0002-1844-0464
}

Submetido em: 29-11-2016 / Aceito em: 14-12-2016 / Publicado em: 01-03-2017.

\begin{tabular}{l|l|l|l|l|l|l} 
(C) Rev. Inter. Educ. Sup. & Campinas, SP & v.3 & n.1 & p.134-149 & jan./abr. 2017 & ISSN 2446-9424 \\
\hline
\end{tabular}


PALAVRAS-CHAVE: Música brasileira. Ambiente virtual de aprendizagem. Educação presencial. Educação a distância.

\begin{abstract}
The purpose of this study is to present the results using Moodle - UFAL as supporting tool in the Brasilian Music course of Federal University of Alagoas. In Introduccion, there is a grounds on the use of ICT to pedagogic renovation. The researches criticize tradicional teaching focused on the teacher and defend the joining of face-to-face education and distance-learnining, to take advantage of resources. This research to get question: such as use Moodle and the resources of ICT translate into an expressive result in the Brazilian Music presencial course? In the Materials and Methods section, were used lessons in Moodle - UFAL with handouts for reading, questionnaires, video-documentaries, podcasts, wikis, a group for the WhatsApp class, and a semistructured research questionnaire for students. In the Results and Discussions section, the students' answers to the research questionnaire are made available and analyzed, as well as the participation in the classes proposed in AVA Moodle - UFAL in the first and second bimerals in the form of graphs and percentage. In the Concluding Remarks, we conclude that the use of the Moodle - UFAL became a place of meeting and discussion of the students and the teacher, especially in the second two months when the virtual resources were expanded.
\end{abstract}

KEYWORDS: Higher education. Brasilian music. Virtual lerning environment. Face-to-face education. Distance-lerning.

\title{
RESUMEN
}

Este artículo tiene como objetivo presentar los resultados en el uso de Moodle - UFAL como herramienta de apoyo para hacer frente en la assignatura Música Brasileña en el Curso de Música de la Universidad Federal de Alagoas - UFAL. En la Introducción, existe una justificación para el uso de las TIC para la renovación pedagógica. Los autores critican la educación tradicional centrada en el profesor y abogan por la unión entre el aula y el aprendizaje a distancia, en una combinación de recursos. La investigación es para discutir la siguiente pregunta: ¿cómo el uso de Moodle y recursos TIC se traduce en resultados significativos en la assignatura Música Brasileña? En la sección Materiales y Métodos, clases fueron utilizados en el Moodle - UFAL con folletos para la lectura, cuestionarios, foros, documentales de vídeo, podcasts, wikis, un grupo de la clase en WhatsApp, y una encuesta cuestionario semiestructurada para los estudiantes. En la sección Resultados y Discusión, están disponibles y se analizaron las respuestas de los estudiantes a la investigación cuestionario, y la participación en las clases propuestas en Moodle - UFAL el primer y segundo período del semestre en gráficos y porcentajes. En las Consideraciones Finales, se concluye que el uso de Moodle - UFAL se ha convertido en un lugar de encuentro y discusión de los estudiantes y el profesor, sobre todo en el segundo período del semestre, cuando se ampliaron los recursos virtuales. Por lo tanto, el uso de Moodle resultó ser una poderosa herramienta para la enseñanza, el aprendizaje y la interacción.

PALABRAS CLAVE: Enseñanza superior. Ambiente virtual de aprendizaje. Educación presencial. Educación a distancia.

\section{INTRODUÇÃo}

O presente artigo tem como objetivo analisar o rendimento dos alunos com o uso do ambiente virtual de aprendizagem (AVA) Moodle - UFAL como ferramenta de apoio na disciplina Música Brasileira do Curso de Música da Universidade Federal de Alagoas UFAL. A organização da referida disciplina auxiliada por recursos das TIC permitiu verificar como o ambiente virtual de aprendizagem contribuiu para a formação dos acadêmicos e para a condução das estratégias metodológicas. 
De acordo com os pressupostos de Lévy (1993), Behrens (2013), Moran (2013), Gohn (2011), viemos discutir a seguinte pergunta da pesquisa: de que maneira o uso do AVA Moodle - UFAL e os recursos das TIC se traduzem em resultado expressivo no rendimento dos alunos na disciplina presencial Música Brasileira do Curso de Música da UFAL? Neste artigo, pretende-se apresentar as reflexões geradas pela efetivação dessa disciplina no período letivo 2016.1.

Atualmente as diferentes situações educacionais no Brasil têm levado professores de música a rever sua atuação pedagógica ao combinar suas habilidades com o uso de recursos das TIC em sua prática docente e melhorar a qualidade do ensino nos cursos, faculdades e universidades.

Pierre Lévy (1993), o conhecimento poderia ser apresentado de três formas diferentes: a oral, a escrita e a digital. Em busca de renovação na prática pedagógica é necessário que professores reconheçam essa nova dimensão que as novas tecnologias digitais proporcionam na educação. Para Behrens (2013, p. 80-81),

Em tal situação, o professor precisa saber que pode romper barreiras mesmo dentro da sala de aula, criando possibilidades de encontros presenciais e virtuais que levem o aluno a acessar as informações disponibilizadas no universo da sociedade do conhecimento. A rede informatizada contempla o registro e a manipulação dinâmica das informações escritas, sonoras e visuais combinadas. O docente precisa servir-se da informática como instrumento de sua prática pedagógica, consciente de que a lógica do consumo não pode ultrapassar a lógica da produção do conhecimento. Nessa ótica, o computador e a rede devem estar a serviço da escola e da aprendizagem.

Atualmente, instituições de ensino e professores têm sido desafiadas a melhorar a qualidade da prática docente com o uso das tecnologias que se ajustem e sejam flexíveis a cada aluno. Ao abordar o assunto Moran (2013, p. 30) faz as perguntas:

Como conciliar mobilidade e espaços e tempos previsíveis? Por que precisamos estar sempre juntos para aprender? (...). Em vez de sermos contrários, por que não experimentamos modelos mais flexíveis? Por que obrigar os alunos a irem à escola todos os dias e repetirem os mesmos rituais nos mesmos lugares?.

$\mathrm{O}$ autor critica o ensino tradicional centrado no professor e defende a aprendizagem participativa e integrada, numa junção entre educação presencial e a distância. Ainda faz referência ao uso dos ambientes virtuais de aprendizagem, como o Moodle, que chama de formais, e das tecnologias denominadas 2.0, que chama de informais, como os blogs, podcasts, wikis dentre outros, numa combinação desses dois tipos de recursos.

Da mesma forma, as redes sociais, grupos e comunidades virtuais são amplamente utilizados na educação. O professor tem a oportunidade de atuar além da sala de aula, sempre

n.1 $13.134-149$


em contato com seus alunos. Segundo Gohn (2015, p. 114), “o papel do professor fica distribuído entre organizadores de materiais, produtores eventuais de vídeos no YouTube, fóruns de discussão e demais websites voltados para educação musical.”

De acordo com Gohn (2011) as oportunidades de aprender música atualmente são facilitadas com a internet. Conseguir informações e enviá-las, bem como esclarecer dúvidas sobre as diversas áreas de estudo musical estão cada vez mais ao alcance de todos. Segundo o autor, os meios de comunicação musical provocaram o aparecimento de diversos sistemas de ensino da música através de softwares educacionais e websites. Ao utilizar o ambiente virtual de aprendizagem Moodle, o pesquisador confirma a praticidade da plataforma, grande capacidade de organização de conteúdos e formatações diferenciadas para cada curso. Gohn (2011, p. 157) mostra que o Moodle serve "como meio de acesso aos conteúdos, (...), meio para divulgar as tarefas, (...), como meio para realização das atividades virtuais, (...), e como meio comunicação entre professor, tutores e alunos".

Ao usar o ambiente virtual de aprendizagem tanto o professor quanto o aluno são estimulados a "aprender a aprender" (BEHRENS, 2013, p. 77), numa busca de produção autônoma de conhecimento e uso adequado da vasta quantidade de informações disponíveis na rede. Ao docente cabe um planejamento que contemple "atividades diferenciadas, focadas em experiências, pesquisa, colaboração, desafios, jogos, múltiplas linguagens, e um forte apoio de situações reais e simulações" (MORAN, 2013, p. 32). O autor afirma que a escolha de materiais adequados e reconhecidos por especialistas é importante ao planejar as etapas do curso e disciplina. Quanto ao aluno, Behrens (2013, p. 77) afirma que "precisa ultrapassar o papel passivo, de escutar, ler, decorar, e de repetidor fiel dos ensinamentos do professor e tornar-se criativo, crítico, pesquisador e atuante, para produzir conhecimento." Os pesquisadores reconhecem o papel ativo tanto do professor quanto do aluno.

Partindo do ponto de vista do que foi exposto até o momento, esse artigo vem discutir a seguinte problemática através da pergunta da pesquisa: de que maneira o uso do AVA Moodle - UFAL e os recursos das TIC se traduzem em resultado expressivo na disciplina presencial Música Brasileira do Curso de Música da Universidade Federal de Alagoas? Como objetivo geral, pretendemos investigar o aproveitamento dos alunos na disciplina presencial Música Brasileira do Curso de Música da Universidade Federal de Alagoas com a aplicação de atividades no AVA Moodle - UFAL e recursos das TIC no período 2016.1.

\section{MATERIAIS E MÉTODOS}

\section{Materiais}

Para realização da pesquisa foram utilizados questionários no AVA Moodle - UFAL com questões do tipo ensaio, múltipla escolha, respostas embutidas, verdadeiro ou falso, 
fóruns, vídeos-documentários, podcasts, wikis, um grupo para a turma no WhatsApp, e um questionário semiestruturado de pesquisa para os alunos.

\section{Métodos}

A pesquisa se desenvolveu através de um levantamento de dados sobre a freqüência às aulas presenciais, análise da participação nas atividades propostas no AVA Moodle - UFAL e em questionário semiestruturado.

\section{RESULTADOS E DISCUSSÕES}

A seguir são apresentados os resultados obtidos com o levantamento de dados sobre a freqüência, a participação nas atividades propostas no ambiente virtual de aprendizagem e em questionário semiestruturado com os alunos da disciplina Música Brasileira do Curso de Música da Universidade Federal de Alagoas (UFAL). 


\section{Primeiro Bimestre}

A disciplina Música Brasileira do Curso de Música - Licenciatura da UFAL no ano de 2016 ( $1^{\circ}$ semestre) tem carga horária de 45 horas ( 3 horas/semanais) com turma de 22 alunos. O período de aulas a ser pesquisado no presente artigo inicia-se a partir do dia 23 de junho de 2016 e se encerra no dia 22 de setembro de 2016. De acordo com o plano de curso da disciplina nos anos anteriores não constava a utilização de ambientes virtuais de aprendizagem nem de recursos de educação a distância. A disciplina era ministrada através de textos e livros consagrados da História da Música Brasileira.

A partir dessa constatação foi elaborado um plano de curso com base em quinze apostilas do curso de História da Música Brasileira do Instituto de Artes da Unesp de autoria do musicólogo Paulo Castagna ${ }^{2}$. Na primeira aula foram feitos esclarecimentos sobre a metodologia de trabalho a ser utilizada deixando claras as dúvidas e questionamentos dos alunos quanto à utilização do AVA Moodle UFAL. Com base nesse material e apoiado em leituras complementares de livros História da Música Brasileira, foram organizadas aulas disponibilizadas semanalmente. Nessas aulas (tópicos) estava disponível o texto sobre o assunto da semana, um questionário aberto (tipo ensaio) sobre o texto e um fórum de discussões dos alunos e professor. Além dessas atividades, também foram colocados vídeosdocumentários sobre Música Brasileira a cada duas aulas. Para cada aula o prazo de encerramento e envio das atividades era de quinze dias a contar da data de postagem.

Nas aulas presenciais semanais havia discussões e comentários sobre as respostas dos questionários e mensagens nos fóruns postados pelos alunos. A partir da segunda aula foi estabelecida a formação de grupos de cinco alunos para apresentações seminários semanais dos textos designados pelo professor, que se iniciaram no dia 14 de julho de 2016 e se estenderam até o dia 25 de agosto de 2016, sendo sete semanas de apresentações de seminários que abordaram sete apostilas (apostila 4 a 10). No dia 26 de agosto encerrou-se o primeiro bimestre de aulas consolidada pela AB1 (Avaliação Bimestral 1).

No primeiro bimestre houve 27 aulas presenciais (de 23 de junho de 2016 a 25 de agosto de 2016) contando com 22 alunos matriculados. Na análise das frequências dos alunos $36 \%$ (8 alunos) já haviam sido reprovados por falta no primeiro bimestre, e 23\% (5 alunos) estavam pendentes com 3 faltas para serem reprovados, 18\% (4 alunos) não tiveram nenhuma falta, e $23 \%$ (5 alunos) tiveram duas faltas. A disciplina presencial Música Brasileira possui 45 horas total, sendo o aluno reprovado se obter a mais de $25 \%$ das atividades didáticas no semestre letivo.

Ainda no primeiro bimestre, as atividades realizadas no AVA Moodle - UFAL foram postadas seis aulas (tópicos) com apostila, questionário aberto (tipo ensaio), um fórum para

${ }^{2}$ Disponível em: <https://archive.org/details/ApostilasDoCursoDeHistriaDaMsicaBrasileiraIaunesp〉. 
discussões em cada aula, além de um vídeo-documentário a cada duas aulas. Em relação à participação dos alunos nesse período obtivemos os seguintes resultados: dos seis questionários 32\% (7 alunos) responderam dois questionários, $41 \%$ ( 9 alunos) responderam a todos os questionários, $27 \%$ (6 alunos) responderam entre quatro e cinco questionários.

Quanto à participação nos fóruns no primeiro bimestre, 5\% (1 aluno) participou de todas as discussões, 32\% (7 alunos) não participaram das discussões, 41\% (9 alunos) participaram entre três e cinco discussões, e 22\% (5 alunos) participaram uma vez dos fóruns.

\section{Segundo Bimestre}

A partir do início do segundo bimestre, que se iniciou no dia 29 de agosto de 2016 e se estendeu até o dia 07 de novembro de 2016, foram planejadas atividades diferenciadas primeiro bimestre. Além de disponibilizar as apostilas, os questionários foram modificados para questões dos tipos múltipla escolha, respostas embutidas, verdadeiro ou falso e ensaio, além dos fóruns e dos vídeos-documentários, o professor acrescentou podcasts, wiki e criou um grupo para a turma no WhatsApp.

Com essas modificações foram observadas algumas mudanças no comportamento dos alunos. À medida que os assuntos avançavam e os conteúdos eram disponibilizados no AVA Moodle - UFAL houve aumento do número de alunos que responderam aos questionários dentre os que menos participavam no primeiro bimestre. Da mesma maneira, a participação nos fóruns aumentou em relação ao primeiro bimestre com atenção às discussões levantadas pela turma e aprofundamento nos assuntos. Como afirma Rodrigues et al. (2011) em sua pesquisa com a plataforma Moodle e material didático multimídia, "A princípio, os alunos não confiaram que a interação com o Moodle e a utilização de material de multimídia fossem capazes de melhorar a absorção do conteúdo", mas ao passar do tempo perceberam que esses recursos se tornaram necessários devido à densidade do conteúdo, e lhes permitiram adaptar seus horários.

Além desses recursos, o professor elaborou um questionário de pesquisa para avaliar a opinião dos alunos quanto ao uso do AVA Moodle - UFAL como ferramenta de apoio, dentre outros aspectos.

Quadro 1. Perguntas do questionário de pesquisa

\begin{tabular}{|l|l|}
\hline & Quantas horas por semana, em média, você utiliza a internet? \\
a. & Menos de 1 hora \\
QUESTÃO 1 & b. Entre 1 e 5 horas \\
& c. Entre 5 e 10 horas \\
& d. Entre 10 e 20 horas \\
& e. Acima de 20 horas \\
\hline
\end{tabular}

Fonte: Elaborado pelo autor

\begin{tabular}{l|l|l|l|l|l|l} 
(C) Rev. Inter. Educ. Sup. & Campinas, SP & v.3 & n.1 & p.134-149 & jan./abr. 2017 & ISSN 2446-9424 \\
\hline
\end{tabular}


Quadro 1. Perguntas do questionário de pesquisa

\begin{tabular}{|l|l|}
\hline QUESTÃO 2 & $\begin{array}{l}\text { Você utiliza ou já utilizou o AVA Moodle UFAL em outras disciplinas ou outros } \\
\text { cursos além de Música Brasileira? Quais? }\end{array}$ \\
\hline QUESTÃO 3 & $\begin{array}{l}\text { Você acha que a estrutura da disciplina Música Brasileira no AVA Moodle UFAL } \\
\text { possibilita a interação entre membros e facilita a aprendizagem? }\end{array}$ \\
\hline QUESTÃO 4 & $\begin{array}{l}\text { Você considera que a disciplina Música Brasileira e outras disciplinas } \\
\text { disponibilizadas no AVA Moodle UFAL desenvolvem objetivos educacionais, no } \\
\text { sentido de ter conteúdos a se aprender/ensinar? }\end{array}$ \\
\hline QUESTÃO 5 & $\begin{array}{l}\text { As discussões entre os alunos e os conteúdos colocados no AVA Moodle UFAL na } \\
\text { disciplina Música Brasileira e outras disciplinas são suficientes para eles se } \\
\text { relacionarem, buscar informações, aprender e ensinar? }\end{array}$ \\
\hline QUESTÃO 6 & $\begin{array}{l}\text { Você pode destacar alguma situação de aprendizagem vivida com o uso do AVA } \\
\text { Moodle UFAL? }\end{array}$ \\
\hline QUESTÃO 7 & $\begin{array}{l}\text { Como você considera sua participação nas atividades propostas no AVA Moodle } \\
\text { UFAL na disciplina Música Brasileira? }\end{array}$ \\
\hline QUESTÃO 8 & \begin{tabular}{l} 
Você acredita ser possível aprender e ensinar no AVA Moodle UFAL? Por quê? \\
\hline QUESTÃO 9
\end{tabular} $\begin{array}{l}\text { No seu entendimento, o que leva os alunos a participarem das atividades no AVA } \\
\text { Moodle UFAL? }\end{array}$ \\
\hline QUESTÃO 10 & $\begin{array}{l}\text { Na sua experiência, o que leva os alunos a NÂO participarem das atividades no } \\
\text { AVA Moodle UFAL? }\end{array}$ \\
\hline QUESTÃO 11 & $\begin{array}{l}\text { Em sua opinião, de que maneiras o uso do AVA Moodle UFAL como ferramenta de } \\
\text { apoio a disciplinas presenciais poderia ajudar você melhorar seu rendimento nas } \\
\text { avaliações e em relação à frequiência às aulas? }\end{array}$ \\
\hline
\end{tabular}

Fonte: Elaborado pelo autor

A primeira questão teve como objetivo conhecer a média de horas semanais que os alunos utilizam a internet. Do total de respostas obtidas, $42 \%$ dos alunos responderam que utilizam a internet entre 10 e acima de 20 horas por semana. Do total de alunos, apenas $8 \%$ utilizam a internet menos de uma hora por semana, sendo que todos os alunos têm acesso à internet semanalmente. A figura 1 ilustra as respostas.

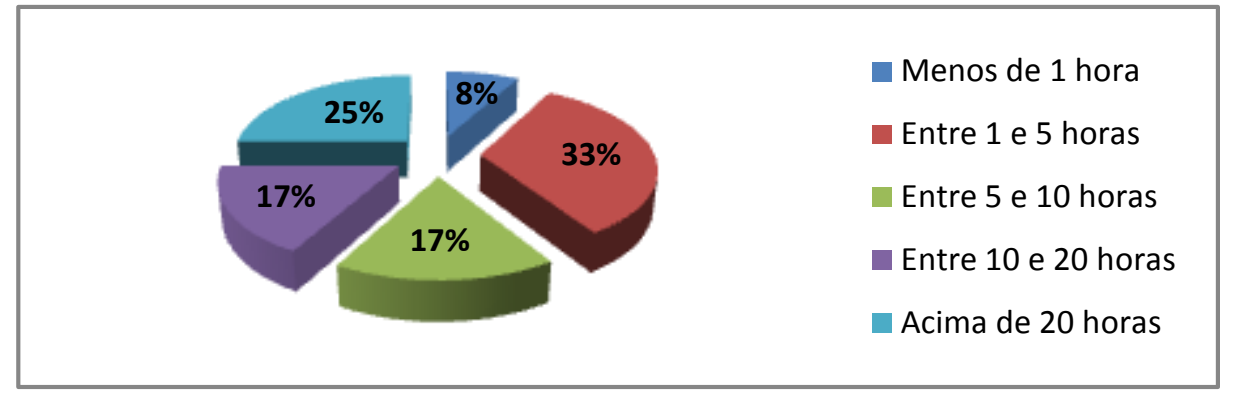

Figura 1. Utilização semanal da internet Fonte: Elaborado pelo autor

Na segunda questão, todos os alunos afirmaram que já utilizaram ou utilizam o AVA Moodle - UFAL em outra(s) disciplina(s) além de Música Brasileira ou em outros cursos de outras instituições. No entanto, há consenso quanto ao uso do Moodle apenas como repositório, para envio e recebimento de materiais. Segundo Gohn (2015, p. 114), "o papel do professor fica distribuído entre organizadores de materiais, produtores eventuais de vídeos no

\begin{tabular}{l|l|l|l|l|l|l} 
(C) Rev. Inter. Educ. Sup. & Campinas, SP & v.3 & n.1 & p.134-149 & jan./abr. 2017 & ISSN 2446-9424 \\
\hline
\end{tabular}


YouTube, fóruns de discussão e demais websites voltados para educação musical". Lisbôa et al. (2009) em sua pesquisa constatou que na amostra de professores pesquisados, "a maior parcela não recorre ao uso da plataforma Moodle", e que os que fazem uso não aproveitam todos os recursos disponíveis. Os professores pesquisados ainda afirmaram que apesar dos benefícios trazidos pelo Moodle, a plataforma "demanda muito tempo para a elaboração de atividades". Dessa forma, os docentes acabam por trabalhar apenas com envio e recebimento de materiais.

$\mathrm{Na}$ terceira questão, os vinte e dois alunos da turma concordam que a estrutura, como a disciplina Música Brasileira no AVA Moodle - UFAL foi planejada, possibilita a interação entre membros da turma e facilita a aprendizagem. No entanto, algumas ressalvas foram feitas por três alunos:

\footnotetext{
- "Possibilita a interação, mas não a obriga. A interação forçada faz com que a participação seja mais breve possível, com análises e respostas pouco trabalhadas." - "Não facilita a aprendizagem porque isso depende da ação e interesse do usuário, facilita o acesso aos materiais de estudo, e a possibilidade de continuar o estudo fora da classe de aula."
}

Delgado (2009) em sua análise dos procedimentos metodológicos com a utilização do Moodle, constatou que a utilização da plataforma promoveu interação entre professor e aluno, mas não promoveu interação entre aluno e aluno no ambiente virtual. Segundo esses autores, é a inserção de novas práticas e recursos aumentam a interação entre alunos. De fato, é pertinente essa observação, pois a disciplina Música Brasileira no AVA Moodle - UFAL foi planejada para que o professor tenha a certeza de que as respostas aos questionários partiram da efetiva leitura do texto da aula. Outro aluno fez a seguinte observação:

\footnotetext{
- "Facilita sim a interação de todos (dos que respondem os questionários), pois para poder responder os questionários é preciso que estude os assuntos e logo depois seja discutido no AVA. É muito bom mesmo para estudo a distância. A compreensão fica até melhor, pois na sala de aula ficará mais fácil interação."
}

Já em relação aos fóruns, os questionamentos e discussões que surgiram partiram do embasamento no texto e no questionário. $\mathrm{O}$ aluno que não leu o texto e não respondeu às questões terá uma participação pouco aprofundada no fórum. Além disso, foram observadas nos fóruns opiniões contrárias ao autor, embasadas em outras fontes e autores, o que levou a questionamentos na sala de aula. Em resposta à terceira questão, outra aluna respondeu: "Sim. Faz com que realmente os textos sejam lidos e com o fórum sejam discutidos algumas questão importantes". Gohn (2011), em seu livro sobre ensino da percussão a distância, constatou que a maioria dos alunos considerou os fóruns como "interessante" e "útil", mesmo assim avaliou que as discussões extrapolaram assuntos planejados e tornou público questões particulares do ensino da percussão de acordo com a vivência e experiência de cada aluno. Em nossa pesquisa na disciplina Música Brasileira, caso semelhante aconteceu em relação aos alunos que tiveram pouco aprofundamento e participação nos fóruns e tentaram desqualificar esse recurso, mas que ao analisar o real motivo estava a falta de leitura e

n.1 p.134-149


resposta aos questionários.

A quarta questão, tratou de avaliar se os conteúdos disponibilizados na disciplina Música Brasileira atingiram seus objetivos. Os vinte e dois alunos responderam positivamente e afirmaram que as apostilas escolhidas pelo professor facilitaram a aprendizagem. Em suas respostas destacaram os textos como "bem fundamentados e acadêmicos" e tratados de uma "forma específica". Afirmaram que os questionários ajudaram a fixar pontos específicos do texto que "passaram despercebidos na leitura". Esse resultados obtidos com o Moodle na disciplina Música Brasileira contrasta com os resultados obtidos por Rodrigues et al. (2011) com o uso do Moodle, os quais revelam que a maioria dos alunos não se entusiasmaram, não se sentiram incentivados para participar de debates, não favoreceu a liberdade de aprendizagem e não tornou a resolução de atividades mais rápida.

Na quinta questão, 58\% dos alunos responderam que as discussões entre os alunos e os conteúdos no AVA Moodle UFAL na disciplina Música Brasileira são suficientes para se relacionarem, buscar informações, aprender e ensinar. Enquanto que $42 \%$ disseram que os conteúdos trabalhados são insuficientes (Figura 2).

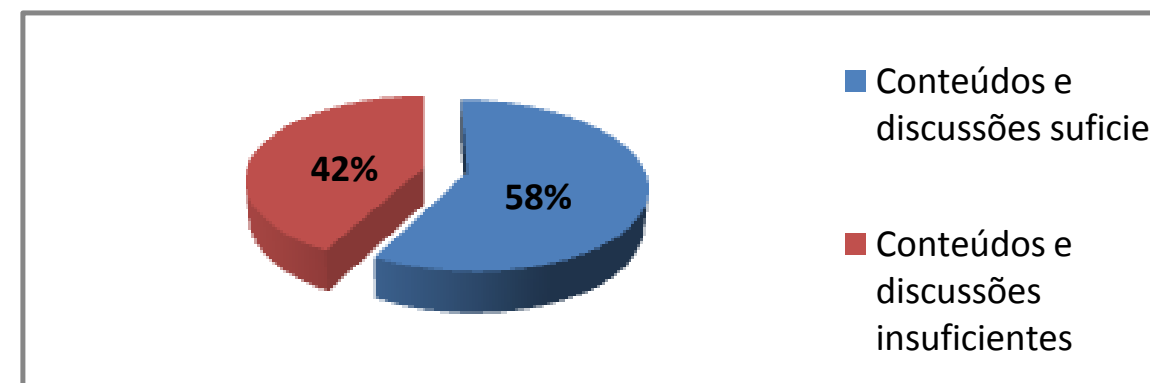

Figura 2. Conteúdos e discussões no AVA Moodle UFAL

Fonte: Elaborado pelo autor

Moran (2013) afirma que a escolha de materiais adequados e reconhecidos por especialistas é importante ao planejar as etapas do curso e disciplina. Dessa forma, acreditamos que as apostilas, textos e livros selecionados para a disciplina Música Brasileira cumpriram seus objetivos e concordou com a afirmação do autor. De maneira geral, os alunos reconheceram que quando os conteúdos bem escolhidos e bem trabalhados servem para ser usados em sua vida profissional. Destaco algumas respostas:

\footnotetext{
- "As discussões entre os alunos sobre essa disciplina tem sido muito importante para evolução de cada aluno. Têm despertado em cada um o desejo de buscar mais conhecimentos, respostas por meios de pesquisas."

- "É importante, mas não é o suficiente, precisa de mais avançar nessa idéia, só vem a nos agregar valores no aprendizado."

- "Nem sempre, pois na maioria das vezes temos que beber em outras fontes para chegarmos em um denominador comum."

- "Claro que ajuda muito o relacionamento entre nós, os conteúdos expostos fazem com que haja um cuidado na interpretação dos textos, e facilita também o posicionamento de nossas discussões, nossas ideias e em questões proposta na matéria, mas também o contato real diariamente vai completar esse relacionamento,
} 
em aprender e passar os conhecimentos."

- "Não são suficientes por dependerem exclusivamente do interesse da turma em participar. Pode funcionar muito bem para uns e muito mal para outros. Quanto ao repositório para conteúdos e arquivos de consulta eu acho perfeito."

$\mathrm{Na}$ sexta questão, todos os alunos da turma destacaram situações de aprendizagem vividas com o uso do AVA Moodle - UFAL. Afirmaram que através dos fóruns foi possível aprender com a opinião dos outros alunos, mesmo tendo lido o mesmo texto. Destacam que o fórum é uma oportunidade de defender seu ponto de vista em relação à discussão levantada pelos colegas e em relação ao próprio texto em confronto com outras fontes e autores. Gohn (2011), destaca os fóruns como "lugar" de extrapolação de assuntos e conscientização de elementos que vão além da aula. Scotti (2016) afirma que, nesses "locais" há uma aprendizagem mais flexível e diversificada, onde os alunos compartilham suas "experiências próprias sem esperar a palavra final do orientador".

$\mathrm{Na}$ sétima questão, os alunos responderam sobre sua participação nas atividades propostas no AVA Moodle - UFAL na disciplina Música Brasileira. Nas respostas destacaram as principais dificuldades que os impedem melhorar seu rendimento:

\footnotetext{
- "Minha participação no AVA não tem sido muito ativa, tenho tido algumas dificuldades em questão de ter um tempo para ler os textos, pois não consigo ler em qualquer ambiente, são tipos de texto que para compreendê-los preciso de bastante atenção e uma leitura tranquila."

- "Bem ativa todas as questões propostas eu as realizo, apesar de muitas vezes fazer os textos em cima do prazo de entrega eu procuro sempre realizá-los."

- "Esse semestre, tive muita dificuldade de fazer questões no AVA. Estou sem notebook."

- "Sinceramente, acho que preciso melhorar a minha participação, como anteriormente já declarei das minhas dificuldades em ter intimidade nessas atividades virtuais proposta nesse sistema, mas tenho plena consciência da necessidade de melhorar a cada dia, gostaria de salientar de que em uma ocasião não consegui enviar o questionário em tempo por não saber enviar."

- "Às vezes demoro para responder devido a estudos de outras disciplinas, mas isso não implica no aprendizado que tenho e minha participação é constante no AVA."

- "Se eu tivesse mais tempo, por causa de meu problema pessoal, eu teria me empenhado mais, de qualquer maneira vou tirar todas as xerox dos textos para levar para minha vida toda."
}

Dentre as principais dificuldades apontadas, destacamos a falta de tempo para ler os textos, envio das questões e fóruns dentro dos prazos de entrega; indisponibilidade de computador ou notebook; dificuldade de manuseio do computador, programas e atividades virtuais; estudos de outras disciplinas; e problemas pessoais. Alguns autores em suas pesquisas concordam com nossos resultados. Paiva, Santos e Barros (2013), constataram que os alunos tornam-se resistentes ao uso do Moodle devido à escassez de tempo e vivência com as ferramentas da plataforma. Já a pesquisa de Gohn (2011) aponta a falta de habilidade e manuseio de programas e novas tecnologias para a produção de vídeos e áudios, e também revela problemas técnicos e a falta de equipamentos como fatores para não entregar tarefas dentro do prazo. Devido a isso, o pesquisador teve que ampliar os prazos para entrega. Nossa pesquisa com a disciplina Música Brasileira indica que a maioria dos alunos pesquisados se 
sentem comprometidos com a rigidez dos prazos estabelecidos, que no nosso caso foi duas semanas, a contar da data de postagem. Ao adotarmos critérios gerais de impessoalidade, buscamos obter resultados reais para a pesquisa e avaliação. Dessa forma, houve uma conscientização dos alunos para o cumprimento do prazo, que insistentemente pediam a dilatação do tempo para entrega. Mesmo assim, dez alunos realizaram a reavaliação devido ao não cumprimento dos prazos.

Sobre a questão oito, todos os alunos pesquisados confirmam a importância do AVA Moodle - UFAL para o ensino e a aprendizagem. Apontam para a facilidade de acesso aos conteúdos e às tarefas como essenciais para aprender, mas que apenas complementam a aula presencial. Afirmam também que o ambiente virtual de aprendizagem é uma ferramenta que querem levar para sua vida profissional, pois facilita a interação, a apresentação de conteúdos e o ajuste dos horários às necessidades dos alunos. Já na pesquisa de Rodrigues et al. (2011), seus resultados indicam que inicialmente os alunos pesquisados não perceberam benefício representativo com o uso do Moodle, nem proporcionou liberdade de aprendizagem, e nem tornou mais rápido o cumprimento das tarefas com a utilização da plataforma, mas no decorrer do curso percebem a necessidade de materiais digitais diversos. Carvalho (2008) coloca que o acesso à internet é um fator essencial para tornar mais fácil o acesso às matérias e a relação aluno-professor e aluno-aluno. Sem a certeza que o aluno tem acesso à internet, o professor não tem como garantir comunicação sem comprometer resultados. Assim, o uso adequado de plataformas de gestão de aprendizagem depende de diversas condições preexistentes, sendo um recurso para o docente e não garantia de aprendizagem para os discentes. Prado e Freitas (2012) afirmam que tal oposição à plataforma deve-se à deficiência no manuseio ou preferência pelo ensino tradicional. Rodrigues et al. (2011) ainda constata que na organização de cursos virtuais o excesso de texto gera desmotivação, sendo necessárias atividades interativas para atender a uma geração de "nativos digitais".

Em relação à questão nove, foram unânimes as respostas dos alunos em relacionar a participação no AVA Moodle - UFAL à avaliação na disciplina, pela obtenção de notas. Mas consideram que essa maneira de avaliar, com data para entrega e participação nas atividades, levou-os a terem mais responsabilidade e regularidade nos estudos. Responderam também que foram levados a participar pelo interesse nas discussões no fórum com outros alunos e para avançar nos conteúdos sobre determinados períodos ou compositores.

\footnotetext{
- "Acredito que a maioria responde e interage pela nota, pois se não responder os questionários fica com nota baixa."

- "O que trás a participação dessas atividades é por serem avaliativas, e pelo compromisso que temos em participar das atividades que nos são propostas levando em consideração que são meios que nos ajudarão a buscar mais sobre os conteúdos."

- "Sinceramente, há uma obrigação dos alunos acessarem o AVA para obtenção de notas, o que não é interessante, mas essa atividade sendo cada vez mais executada irá colocar esse pensamento cair por terra e isso será muito bom.”

- "Na verdade o professor impõe como metade da nota e os alunos aceitam. Isso diz tudo...Mas também têm: complemento de ensino abordado na aula."
}

v.3

n. 1

p.134-149

jan./abr. 2017

ISSN 2446-9424 
Em sua pesquisa, Costa e Mendonça (2014) constataram que as notas da maioria dos alunos não aumentaram com o uso do Moodle, contrastando com os resultados de Rodrigues et al. (2011) que, no período de dois anos, obteve redução de $10 \%$ no índice de reprovação. Costa e Mendonça (2014) apontam uma possível causa para tal divergência a utilização dos diversos recursos oferecidos pela plataforma Moodle como fator para o aumento das notas. Esta afirmação concorda com os resultados obtidos em nossa pesquisa na disciplina Música Brasileira, em que houve um maior rendimento de notas com a ampliação dos recursos do Moodle do primeiro bimestre para o segundo bimestre, sendo maior a participação dos alunos no segundo bimestre devido ao aproveitamento dessas novas ferramentas elaboradas pelo professor.

Em relação à questão dez, os alunos apontaram os principais motivos que os impediram de participar das atividades no AVA Moodle - UFAL: cansaço físico e mental, falta de tempo pelo trabalho, indisponibilidade de computador, indisponibilidade de internet, falta de responsabilidade, e falta de familiaridade com a tecnologia (Figura 3).

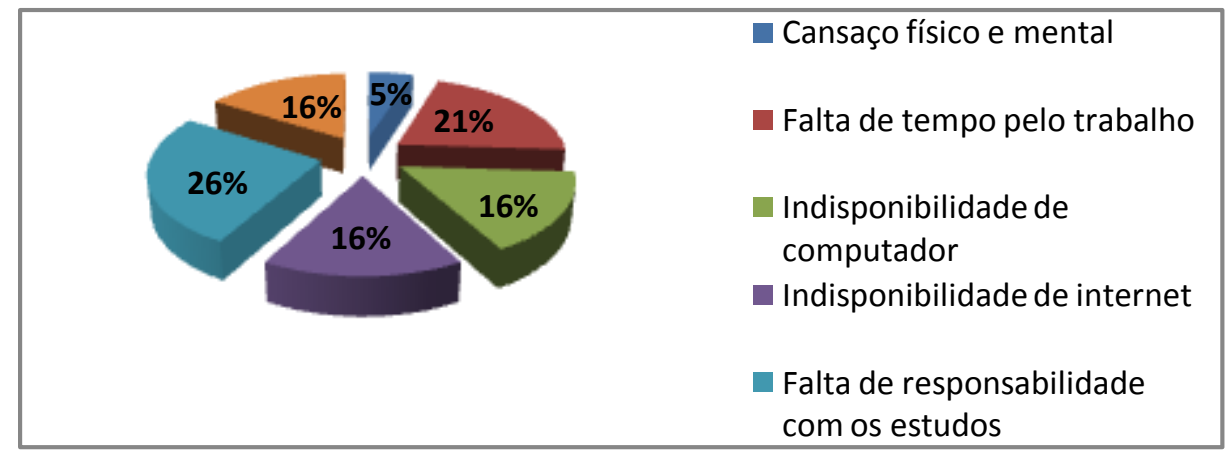

Figura 3. Principais motivos de não participação no AVA Moodle - UFAL

Fonte: Elaborado pelo autor

Quanto à questão onze, os alunos ressaltam que, o uso do AVA Moodle - UFAL além de ajudar nos conteúdos e atividades propostas pelo professor, poderia, de certo modo, flexibilizar a freqüência às aulas.

- "Em relação à frequência nas aulas, como o curso é presencial, claro que precisamos estar nas aulas, mas, há exceções em que se podia ajudar em relação à frequência."

- "O uso do AVA UFAL me possibilita ter os conteúdos para que em caso de uma falta justa eu tenha contato com o que foi passado em sala de aula e por isso não fico perdida entre os assuntos, ainda mais por eles se complementar."

- "Na minha opinião se o aluno vier a responder o questionário que for estabelecido da mesma semana de forma correta,ele não podendo estar presente na aula,poderia ter pelo menos $50 \%$ da falta retirada."

- "Bom! Só eu sei como é difícil estudar e trabalhar ao mesmo tempo, no meu caso com as minhas atividades profissionais, pois tenho que cumprir o expediente no CBMAL (Corpo de Bombeiros Militar de Alagoas) no mesmo horário das aulas, se bem que existe um respaldo por lei, mais mesmo assim tenho que conciliar, Quartel/UFAL a todo momento; graças a Deus tenho esse recurso que é o AVA

\begin{tabular}{l|l|l|l|l|l|l} 
(C) Rev. Inter. Educ. Sup. & Campinas, SP & v.3 & n.1 & p.134-149 & jan./abr. 2017 & ISSN 2446-9424 \\
\hline
\end{tabular}


ajudando sempre, quando não posso estar na aula, sobre tudo nas avaliações que poderei executar mesmo estando ausente nas aulas, e dependendo do meu desempenho, obterei notas necessárias."

- "Disponibilizando o assunto e um exercício para o aluno que não esteve presente naquele dia de aula, com um prazo para que o mesmo responda e envie. Assim ele não irá se prejudicar e todos continuarão andando juntos."

- "Acho que não substitui a frequência às aulas uma vez que o curso é presencial. O AVA me ajuda no acesso a arquivos para downloads, troca de mensagens de um determinado interesse, realização de avaliações com consulta ou com tempo determinado."

- "Como o AVA serve de apoio para a disciplina presencial, caso haja uma ausência na aula ele poderia ajudar com postagens do que foi abordado na sala. A participação online servirá de muleta e te deixar cair, nem nas notas e nem na frequência."

Do total de alunos da turma, $58 \%$ chegam a supor que a Universidade poderia trazer alternativas em relação às faltas (freqüência) nas disciplinas presenciais que utilizam o AVA Moodle - UFAL como ferramenta de apoio. Os outros $42 \%$ acreditam que o uso do ambiente virtual ajuda apenas na didática do professor e na forma de abordagem da disciplina. Sobre essa questão levantada pelos alunos na disciplina Música Brasileira, não encontramos em nenhuma pesquisa dos autores citados alguma referência ou matéria relacionada, sendo um assunto inesperado e novo para a pesquisa. Entendemos que em cursos presenciais o uso do Moodle como ferramentas de apoio não pode substituir a aula presencial, o que pode ferir legislação vigente e determinações do Conselho Universitário, sendo apenas um recurso a mais para o professor.

\section{CONSIDERAÇ̃̃ES FINAIS}

O objetivo desta pesquisa foi analisar o rendimento dos alunos na disciplina presencial Música Brasileira com o uso do AVA Moodle - UFAL como ferramenta de apoio. A análise dos resultados se deu através da comparação com resultados obtidos por outros autores ao utilizarem a plataforma Moodle em disciplinas de diferentes áreas, inclusive em Educação Musical com duas experiências.

Através destas comparações obtivemos resultados divergentes, como, por exemplo, o aumento das notas, e a percepção dos alunos quanto à importância do Moodle. No entanto, as discussões levantaram como fatores essenciais, para o andamento de disciplinas que utilizam ambientes virtuais de aprendizagem, o acesso de todos os alunos à internet e a habilidade de manuseio de softwares e programas. Concluímos ainda que o uso adequado de ambientes virtuais de aprendizagem depende de diversas condições preexistentes, sendo um recurso para o docente e não garantia de aprendizagem para os discentes. $O$ professor tem papel fundamental nesse processo, pois necessita adaptar-se a uma geração cada vez mais hábil com as novas tecnologias, além de planejar atividades interativas com os recursos e ferramentas disponíveis no Moodle.

Fica evidente que o uso do AVA Moodle - UFAL como ferramenta de apoio na disciplina Música Brasileira ultrapassou a expectativa inicial de apenas servir de repositório e

\begin{tabular}{l|l|l|l|l|l|l} 
(C) Rev. Inter. Educ. Sup. & Campinas, SP & v.3 & n.1 & p.134-149 & jan./abr. 2017 & ISSN 2446-9424 \\
\hline
\end{tabular}


para envio e recebimento de atividades. Transformou-se num lugar de encontro e discussão dos alunos, principalmente no segundo bimestre quando o professor, além das atividades presenciais em sala de aula, ampliou os recursos utilizados para as atividades, havendo maior participação nos questionários e discussões propostas nos fóruns. Dessa forma, o AVA Moodle - UFAL mostrou ser uma ferramenta poderosa para o ensino, aprendizagem e interação.

\section{REFERÊNCIAS}

CARVALHO, A. A. A. Os LMS no apoio ao ensino presencial: dos conteúdos às internações. Revista Portuguesa de Pedagogia, Coimbra, v. 42, n. 2, p.101-122. 2008. Disponível em: <http://iduc.uc.pt/index.php/rppedagogia/article/view/1239>. Acesso em: 26 fev. 2017.

BEHRENS, Marilda Aparecida; MORAN, José Manuel; MASETTO, Marcos T. Novas tecnologias e mediação pedagógica. 21. ed. rev. e atual. Campinas, SP: Papirus, 2013. 171p. (Coleção Papirus Educação).

COSTA, Patrícia de Souza; MENDONÇA, Laura de Souza. O uso da plataforma Moodle como apoio ao ensino presencial. Diversa Prática: Revista Eletrônica da Divisão de Formação Docente, v. 2, n. 1, $1^{\circ}$ sem. 2014. Disponível em: <:http://www.seer.ufu.br/ index.php/diversapratica/article/download/26430/pdf_5>. Acesso em: 26 fev. 2017.

DELGADO, L. M. M.; HAGUENAUER, C. J. Uso da Plataforma Moodle no Apoio ao Ensino Presencial: um Estudo de Caso. Educaonline: Educação e Novas Tecnologias, Rio de Janeiro, v. 4, n. 1, p.11-26, abr. 2010.

GOHN, Daniel Marcondes. Educação musical a distância: abordagens e experiências. São Paulo: Cortez, 2011. 231p.

GOHN, Daniel Marcondes. Meios tecnológicos para a educação não formal de música. In: GOHN, Maria da Glória (Org.). Educação não formal no campo das artes. São Paulo: Cortez, 2015. p. 109-128.

LEVY, Pierre. As tecnologias da inteligência: o futuro do pensamento na era da informática. São Paulo: editora 34, 1993.

LISBÔA, E. S. et al. LMS em contexto escolar: estudo sobre o uso da Moodle pelos docentes de duas escolas do Norte de Portugal. Educação, Formação \& Tecnologias, Monte da Capiraca, Portugal, v. 2, n. 1, p. 44-57, 2009. Disponível em: <http://eft.educom.pt/ index.php/eft/article/view/74>. Acesso em: 26 fev. 2017.

MORAN, José Manuel; MASETTO, Marcos T.; BEHRENS, Marilda Aparecida. Novas tecnologias e mediação pedagógica. 21. ed. rev. e atual. Campinas, SP: Papirus, 2013. 171p. (Coleção Papirus Educação). 
PAIVA, K. C. M. de et al. Percepções de alunos e professores do curso de Administração a respeito da educação à distância: um estudo em uma instituição particular brasileira. Tourism \& Management Studies, Faro, Portugal, v. 1, p. 354-366, 2013.

PRADO, B. M. P. do; FREITAS, F. S. de. O moodle e o ensino à distância: resistência ao uso da ferramenta. In: CONGRESSO NACIONAL UNIVERSIDADE, EAD E SOFTWARE LIVRE, 2012. Anais do... [S.1.]: [s.n.], 2012.

RODRIGUES, L. C et al. Uso de ambiente virtual de aprendizagem como auxílio ao ensino presencial de linguagem de programação. In: WORKSHOP DE PÓS-GRADUAÇÃO E PESQUISA DO CENTRO PAULA SOUZA, 6., 2011. Anais do... Campinas: Centro Paula Souza, 2011. Disponível em: <:http://www.cps.sp.gov.br/pos-graduacao/workshop-de-posgraduacao-e-pesquisa/anais/2011/trabalhos/ti-aplicada/uso-de-ambiente-virtual-deaprendizagem-como-auxilio-ao-ensino.pdf :> Acesso em: 26 fev. 2017.

SCOTTI, Adelson. Violão no espaço virtual: construindo saberes. Curitiba: Editora Prismas, 2016. 196 p. 